\title{
Early diagnosis of diabetic autonomic neuropathy: present and future approaches
}

\author{
G.M ancia ${ }^{1,2,3}$, F. Paleari ${ }^{1}$, G. Parati ${ }^{2,3}$ \\ ${ }^{1}$ Cattedra di Medicina Interna, Universita' di Milano, e Ospedale S. Gerardo, Monza, Italy \\ ${ }^{2}$ Centro di Fisiologia e Ipertensione, IRCCS, Ospedale Maggiore, Milan, Italy \\ ${ }^{3}$ IRCCS, Centro Auxologico Italiano, Milano, Italy
}

This issue of Diabetologia includes a paper by Dr. Aronson on the prognostic significance of diabetic autonomic neuropathy. The paper reviews the evidence that in diabetic patients clinical autonomic neuropathy, i.e. a condition associated with signs and symptoms of visceral autonomic dysfunction, carries an increased risk of mortality. It further reviews the more recent data that this is also the case for subclinical autonomic neuropathy, and that an increased risk of mortality and sudden death (presumably due to cardiac arrhythmias) is typical also of diabetic cardiac autonomic neuropathy, a condition in which the clinical or subclinical autonomic dysfunction is limited to the heart.

The prognostic importance of subclinical cardiac autonomic neuropathy emphasizes the need for a diagnosis of alterations of cardiac autonomic modulation at the earliest possible stage. As mentioned by Aronson, in this context significant progress has been made with the quantification of spontaneous heart rate variability which, in several diabetic patients, is decreased at a time when the more partial estimates of heart rate variations provided by traditional laboratory autonomic tests (e.g. the 30/15-s test, the deep breathing test, etc.) still fall within the normal range [1].

However, the goal of obtaining sensitive markers of cardiac autonomic neuropathy is far from being satisfactorily achieved. 1) Spontaneous heart rate variability does not entirely depend on autonomic cardiac modulation because heart rate variance is usually reduced but not abolished by pharmacological autonomic blockade of the heart [2] or by cardiac surgical denervation by heart transplantation [3].

Corresponding author: Dr. G. Mancia, $1^{\circ}$ Divisione di Medicina, Ospedale San Gerardo dei Tintori, via Donizetti 106, 20052 Monza, Italy
2) A non-autonomic component can also be identified when heart rate variations around 0.1 and $0.2-$ $0.3 \mathrm{~Hz}$ are quantified by power spectral analysis. There is no doubt that heart rate fluctuations around $0.1 \mathrm{~Hz}$ depend on sympathetic modulation of the sinus node because the $0.1 \mathrm{~Hz}$ heart rate power; a) increases in conditions associated with an acute cardiac sympathetic activation such as tilting [4]; b) decreases in conditions characterized by an acute cardiac sympathetic deactivation such as sleep [5, 6]; and c) decreases to a pronounced degree in diseases associated with chronic sympathetic failure such as primary dysautonomias [7]. There is also no doubt that heart rate fluctuations around $0.2-0.3 \mathrm{~Hz}$ are largely determined by vagal cardiac influences because atropine has a marked blunting effect on the $0.2-0.3 \mathrm{~Hz}$ heart rate power which is conversely increased under conditions known to increase vagal tone $[2,5,6,8,9]$. However, as for overall heart rate variability, both 0.1 and $0.2-0.3 \mathrm{~Hz}$ powers are not entirely abolished following pharmacological or surgical 'denervation' of the sinus node [10-14], which indicates that their specificity as autonomic markers is incomplete. Furthermore the vagus nerve is now known to participate not only in the determination of the $0.2-0.3 \mathrm{~Hz}$ but also in the determination of the $0.1 \mathrm{~Hz}$ heart rate power, to a degree inversely related to the respiratory frequency $[2,10,15]$. This questions these two powers being separate markers of vagal and sympathetic cardiac influences, respectively; particularly if the respiratory frequency is not concomitantly measured. It also questions the common use of their ratio as the most sensitive marker of sympatho-vagal balance (or imbalance), because the interpretation of this ratio is made difficult by the possible contribution of the same autonomic pathway to both terms of the ratio. Thus, although the 0.1 and the $0.2-0.3 \mathrm{~Hz}$ heart rate powers have been used with favourable results as early markers of cardiac autonomic dysfunction in 
diabetes mellitus [16-19], some false-positive and false-negative diagnoses are probably unavoidable even with this more selective approach to heart rate variability. False-positive diagnosis may originate from a decreased responsiveness of cardiac effector to all stimuli while false-negative diagnosis may originate from the blunting effect of vagal impairment on both $0.2-0.3$ and $0.1 \mathrm{~Hz}$ powers, when the ratio between these powers is used.

Computerized multisignal analysis may allow further improvement in the diagnosis of diabetic cardiac dysautonomia. This approach consists of combined computer analysis of pulse interval (the reciprocal of the heart rate) and systolic blood pressure over periods in which these signals are monitored beat-tobeat, which allows sequences to be identified of four beats or more characterized by: 1) a progressive systolic blood pressure increase with a linearly related increase in pulse interval, and 2) a progressive systolic blood pressure decrease with a linearly related reduction in pulse interval. Data obtained in animals have shown that these sequences may specifically reflect baroreceptor modulation of the sinus node because sino-aortic denervation is followed by their virtual disappearance [20]. This is complemented by several important advantages of a more practical nature; for example, 1) avoidance of external interventions such as the injection of vasoactive drugs to stimulate and de-activate baroreceptors; 2) baroreflex engagement by spontaneous rather than artificial blood pressure variations; 3) baroreflex dynamic assessment by a large number of rather than one or a few observations; and 4) the possibility of obtaining reliable data by beat-to-beat non-invasive monitoring of blood pressure with the subject supine, in relatively short time periods.

Use of the sequence method has allowed an impairment of the baroreceptor-heart rate reflex to be shown under various physiological conditions and in diseases [21-24] in which the impairment became manifest as: 1) a reduced number of sequences; 2) a reduced slope of linear regression relating the change in systolic blood pressure with the change in pulse interval; and 3) a reduced increase in baroreflex sensitivity during sleep $[21,22,25]$.

Interestingly, these three aspects of baroreflex impairment were recently also found in both insulindependent and non-insulin-dependent diabetic patients [26], who had normal traditional tests of autonomic dysfunction and normal or only slightly reduced heart rate variance. This is a promising approach for thus simply and sensitively diagnosing the cardiac autonomic neuropathy induced by diabetes. This may also be the case for data derived from the ratio of pulse interval and systolic blood pressure spectral powers in the frequency regions where these powers are coherent [27, 28], although this measure of reflex autonomic cardiac modulation may be less specific than the measure based on the "sequence" method.

Early identification of cardiac diabetic dysautonomia is important also because having sensitive diagnostic markers of cardiac autonomic dysfunction also means regression of the dysfunction by anti-diabetic treatment to be more easily assessed and different treatments to be more properly compared. However, this will not meet all needs posed by diabetic dysautonomia. A major residual problem is that the diabetes-dependent alteration of autonomic vascular control can be assessed in a much less sensitive fashion than the alteration of cardiac vascular control. Namely, the tests exploring the blood pressure or vasoconstrictor response to sympathetic activation (hand-grip, cold pressor test, etc) are frequently normal when diabetes is of long-duration and other types of autonomic dysfunction are evident. In our studies [26] blood pressure variance was similar in uncomplicated and complicated diabetes, which excludes that a global measure of spontaneous blood pressure variations might be invariably useful. However, in addition to the above multi-signal analysis, also spectral analysis of blood pressure and heart rate oscillations from the lowest to the highest frequencies, i.e. the broad band spectral analysis [29], appears to represent a more promising approach for what should be regarded as a major research goal in this field.

\section{References}

1. Ziegler D (1994) Diabetic cardiovascular autonomic neuropathy: prognosis, diagnosis and treatment. Diabetes Metab Rev 10: 339-383

2. Saul JP, Berger RD, Chen MH, Cohen RJ (1989) Transfer function analysis of autonomic regulation. II: respiratory sinus arrhythmia. Am J Physiol 256: H153-H161

3. Bernardi LF, Keller M, Sanders M, Reddy PS, Meno F, Pinsky MR (1989) Respiratory sinus arrhythmia in denervated human heart. J Appl Physiol 67: 1447-1455

4. Pagani M, Lombardi F, Guzzetti S et al. (1986) Power of spectral analysis of heart rate and arterial pressure variabilities as a marked of sympathovagal interaction in man and conscious dog. Circ Res 59: 178-193

5. Parati G, Castiglioni P, Di Rienzo M, Omboni S, Pedotti A, Mancia G (1990) Sequential spectral analysis of 24 hour blood pressure and pulse interval in humans. Hypertension 16: 414-421

6. Furlan R, Guzzetti S, Crivellaro W et al. (1990) Continuous $24 \mathrm{~h}$ assessment of the neural regulation of systemic arterial pressure and RR variabilities in ambulant subjects. Circulation 81

7. Omboni S, Parati G, Di Rienzo M, Wieling W, Mancia G (1995) Blood pressure and heart rate variability in autonomic disorders: a critical review. Clin Auton Res 5: $1-11$

8. Eckberg DL (1983) Human sinus arrhythmia as an index of vagal cardiac outflow. J Appl Physiol 54: 961-966

9. Katona PG, Jih F (1975) Respiratory sinus arrhythmia: non-invasive measure of parasympathetic cardiac control. J Appl Physiol 39: 801-805 
10. Parati G, Saul JP, Di Rienzo M, Mancia G (1995) Spectral analysis of blood pressure and heart rate variability in evaluating cardiovascular regulation. A critical appraisal. Hypertension 25: 1276-1286

11. Daffonchio A, Franzelli C, Di Rienzo M (1991) Effect of sympathectomy on blood pressure variability in the conscious rat. J Hypertension 9 [Suppl 6]: S70-S71

12. Tulen JHM, Man in’t Veld AJ, Van Roon AM et al. (1994) Spectral analysis of hemodynamics during infusions of epinephrine and norepinephrine in man. J Appl Physiol 76: 1914-1921

13. Bernardi LF, Keller M, Sanders M, Reddy PS, Meno F, Pinsky MR (1989) Respiratory sinus arrhythmia in denervated human heart. J Appl Physiol 67: 1447-1455

14. Kingwell BA, Thompson JM, Kaye DM, McPherson GA, Jennings GL, Esler MD (1994) Heart rate spectral analysis, cardiac norepinephrine spillover and muscle sympathetic nerve activity during human sympathetic nervous activation and failure. Circulation 90: 234-240

15. Saul JP, Berger RD, Albrecht P, Stein SP, Chen MH, Cohen RJ (1991) Transfer function analysis of the circulation: unique insight into cardiovascular regulation. Am J Physiol 261: H1231-H1245

16. Yamasaky I, Ueda N, Kishimoto M et al. (1991) Assessment of early stage autonomic nerve dysfunction in diabetic subjects. Application of power spectral analysis of heart rate variability. Diabetes Res 17: 73-80

17. Ziegler D, Dennehl K, Volksw D, Muhlen H, Spuler M, Gries FA (1992) Prevalence of cardiovascular autonomic dysfunction assessed by spectral analysis and standing tests of heart rate variations in newly diagnosed IDDM patients. Diabetes Care 15: 908-911

18. Bernardi L, Rossi M, Soffiantino F et al. (1989) Cross-correlation of heart rate and respiration versus deep breathing. Assessment of a new test of cardiac autonomic function in diabetes. Diabetes 38: 589-596

19. Pagani M, Malfatto G, Pierini S et al. (1988) Spectral analysis of heart rate variability in assessment of autonomic diabetic neuropathy. J Auton Nerv Syst 23: 143-153

20. Bertinieri G, Di Rienzo M, Cavallazzi A, Ferrari AU, Pedotti A, Mancia G (1988) Evaluation of baroreceptor reflex by blood pressure monitoring in unanesthetized cats. Am J Physiol 254: H377-H383

21. Parati G, Di Rienzo M, Bertinieri G et al. (1988) Evaluation of the baroreceptor heart rate reflex by 24 hour intraarterial blood pressure monitoring in humans. Hypertension 12: 214-222

22. Parati G, Frattola A, Di Rienzo M, Castiglioni P, Pedotti A, Mancia G (1995) Effects of aging on $24 \mathrm{~h}$ dynamic baroreceptor control of heart rate in ambulant subjects. Am J Physiol 268: H1606-H1612

23. Parati G, Di Rienzo M, Castiglioni P et al. (1995) Daily-life baroreflex modulation: new perspectives from computer analysis of blood pressure and heart rate variability. In: Di Rienzo M, Mancia G, Parati G, Pedotti A, Zanchetti A (eds) Computer analysis of cardiovascular signals. IOS Press, Amsterdam pp 209-218

24. Parati G, Mutti E, Frattola A, Castiglioni P, Di Rienzo M, Mancia G (1994) Beta-adrenergic blocking treatment and 24-hour baroreflex sensitivity in essential hypertensive patients. Hypertension 32: 992-996

25. Smyth HS, Sleight P, Pickering GW (1969) Reflex regulation of arterial pressure during sleep in man. Circ Res 24: 109-121

26. Frattola A, Parati G, Paleari F, Gamba P, Ghelfi D, Mancia G (1995) Autonomic abnormalities in diabetic patients: early detection by computer analysis of blood pressure and heart rate variability. J Hypertens 11: 15-19

27. Pagani M, Somers V, Furlan R et al. (1988) Changes in autonomic regulation induced by physical training in mild hypertension. Hypertension 12: 600-610

28. Robbe HWJ, Mulder LJM, Ruddel H, Langewitz WA, Veldman JBP, Mulder G (1987) Assessment of baroreceptor reflex sensitivity by means of spectral analysis. Hypertension 10: 538-543

29. Di Rienzo M, Parati G, Castiglioni P, Mancia G, Pedotti A (1995) The wide band spectral analysis: a new insight into modulation of blood pressure, heart rate and baroreflex sensitivity. In: Di Rienzo M, Mancia G, Parati G, Pedotti A, Zanchetti A (eds) Computer analysis of cardiovascular signals. IOS Press, Amsterdam, pp 68-74 